\title{
Recent Advances in the Martensitic Transformations of Ti-Ni Alloys
}

\section{J. Beyer}

University of Twente, Dept. of Mechanical Engineering, Laboratory of Materials Science, P.O. Box 217, 7500 AE Enschede, The Netherlands

\begin{abstract}
Ti-Ni alloys are the most widely used among many other shape memory alloys. Despite of this fact, the characteristics of the thermoelastic martensite transformation and the related shape memory mechanism have not been well understood, mainly by the lack of single crystal data. Recent results are reviewed on crystallographic aspects of the martensite and R-phase transformation, shape memory mechanism, control of transformation temperatures and deformation behaviour. New achievements concerning the influence of third elements on the transformation behavior, development of high temperature shape memory alloys and the influence of texture on the shape memory behavior are being discussed.
\end{abstract}

\section{INTRODUCTION}

Since the discovery of the shape memory effect (SME) in a Ti-Ni alloy in 1963 it became the most widely used Shape memory alloy (SMA) because it provides the best combination of material properties $(1,2,3)$. The SME and related pseudoelasticity (PE) in Ti-Ni alloys is associated with their thermoelastic martensitic transformations. In fully annealed binary $\mathrm{Ti}-\mathrm{Ni}$ alloys the B2 parent phase transforms directly to the B19' (monoclinic)-phase, the thermomechanically treated or thermal cycled Ti-Ni alloys show a two-step transformation to trigonal R-phase $(4,5,6)$ and to $B 19^{\prime}$ phase $(7,8,9)$. Addition of third elements as $\mathrm{Cu}$ can result in another two-step transformation B2 $\rightarrow$ B19 (orthorhombic) $\rightarrow$ B19' $(10,11,12$ ). The last transformation sequence is also observed in other ternary systems as NiTi Pd (13).

In binary $\mathrm{Ti}-\mathrm{Ni}$ alloys with nickel exceeding 50,5 at $\%$ the parent phase decomposes by slow cooling or by aging at lower temperatures after quenching from high temperatures. The decomposition products involve two metastable phases $\mathrm{Ti} 3 \mathrm{Ni} 4$ and $\mathrm{Ti} 2 \mathrm{Ni3}$ and the stable $\mathrm{TiNi3}$ phase. The Ti3Ni4 phase is important for the SME behaviour, resulting in the all-round effect after constrained aging $(14,15)$. Not only excess of $\mathrm{Ni}$ or third elements can influence the transformation characteristics but also impurities like $\mathrm{C}, \mathrm{O}, \mathrm{N}$, and $\mathrm{H}$ as they might be introduced by the manufacturing process due to the high affinity of $\mathrm{Ti}$ to these elements $(3,16)$ 
Important crystallographic aspects related to the SME are the crystal structures of the R-phase and the martensites $(17,18)$, the crystallography of the mechanism of transformation and selfaccomodation. Recently, single crystals became available and made determination of accurate lattice parameter, lattice correspondence and lattice invariant shear possible $(17,22)$. In practice the SMA will be in a polycrystalline state and therefore it is important to know about the anisotropic behaviour of these materials. A suitable texture can improve the memory response for desired applications $(23,24)$. The ternary Ti-Ni-X alloys for the development of high temperature SMA's have attracted considerable attention in the past few years $(25,28)$. This paper will discuss advances in recent investigations concerning the above mentioned aspects of martensite transformations in $\mathrm{Ti}-\mathrm{Ni}(-\mathrm{X})$ alloys.

\section{TRANSFORMATION SEQUENCE AND CRYSTAL STRUCTURES.}

\subsection{Transformation sequences.}

The parent phase in Ti-Ni alloys which has a CsCl-type B2 superlattice may transform martensitically to three different crystal structures. The transformation can follow different paths:

B2 $\rightarrow$ monoclinic B19, B2 $\rightarrow$ (rhombohedral or) R-phase $\rightarrow$ B19', B2 $\rightarrow$ (orthorhombic) B19 $\rightarrow$ B19' and $\mathrm{B}_{2} \rightarrow \mathrm{R} \rightarrow \mathrm{B} 19 \rightarrow\left(\mathrm{B}_{19}\right)$. The sequence that will be followed is determined by several conditions (32):

1. Variation of Ni content [2]

2. Thermomechanical treatment (cold work + annealing below recrystallization temperatures) $(34,36)$

3. Ageing after solution treatment $(9,15,35)$

4. Thermal cycling $(24,33)$

5. Substitution of alloying elements (as $\mathrm{Cu}, \mathrm{Pd}, \mathrm{Pt})(11,12,13)$

Fully annealed Ti-Ni alloy will transform from B2 $\rightarrow$ B19'. Under certain conditions the B2 lattice changes to an incommensurate phase (without changing the lattice) and subsequently transforms to the R-phase by elongating along any of the $<111>$ directions of the $\mathrm{B} 2$ lattice. Finally the Rphase (or B2-phase) transforms to either the B19' or the B19 phase. (The incomensurate phase falls outside the scope of this paper and will not be discussed).

It is now well established that in $\mathrm{Ni}$ rich $(>50,5$ at \% $\mathrm{Ni}) \mathrm{Ti}-\mathrm{Ni}$ alloys diffusional transformations take place during aging or slow cooling from high temperature.

The precipitation sequence can be written as $\mathrm{B}_{2} \rightarrow \mathrm{T} 3 \mathrm{~N} 4$ (metastable) $\rightarrow$ Ti2Ni3 (metastable) $\rightarrow$ TiNi3 (stable). The temperature decomposition scheme is best illustrated in the T-T-T-diagram of fig. 1

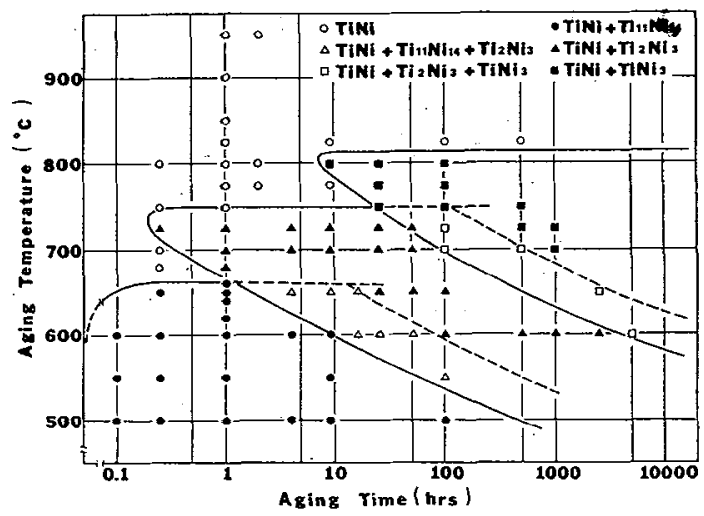

Fig.1 T-T-T-diagram describing the precipitation behaviour for Ti-52Ni (14). 
The $\mathrm{T}_{3} \mathrm{~N}_{4}$ phase (also called X-phase) forms homogeneously in the early stages of aging at low temperatures, coherent with the matrix, as fine platelets (15). Ti2Ni3 forms at higher temperatures inhomogeneously as long platelike precipitates within the grain on blocky shapes on grain boundaries (37). The Ti2Ni3 and TiNi3 are considered to be detrimental for the shape memory properties.

\subsection{Crystal structures.}

The crystal structure of the B19' monoclinic martensite has been controversial for a long time due to lack of single crystal data. Kudoh at al (18) eventually succeeded in producing a single crystal of $\mathrm{Ti}-49,2$ at $\% \mathrm{Ni}$ alloy by a strain-anneal method and making a single crystal of martensite by stress-induced transformation. The structure is monoclinic and belongs to the space group $P 21 / \mathrm{m}$. They determined the lattice parameters to be $a=0.2898, b=0.4108$, $c=0.4646 \mathrm{~nm}$ and $B=97,78^{\circ}$ which is slightly different from those earlier reported particularly with respect to $B(18,38)$. The complicated atomic shuffles (not parallel to the basal phase) results in a three dimensional close-packed structure. The exact atomic positions calculated by Kudoh et.al. are for Ti: $(0,0,0)$ and $(0,1648,0,5,0,5672)$ and for $\mathrm{Ni}:(0,6196,0,0,4588)$ and $(0,5452,0,5,0,0,1084)$.

Accuracy of the structure analysis was evaluated by the reliability factor $R=\frac{\boldsymbol{\Sigma}\left\|F_{o}-F_{c}\right\|}{\left|F_{o}\right|}$.

$F_{o}$ and $F_{c}$ are the observed and calculated structure factors. $R=4.5 \%$ is obtained which is below the $10 \%$ for accurate analysis. The lattice parameters have been proved to be composition dependent $(18,22,23)$. In different Ti-Ni-X alloys the Bain distortion is more or less the same. The atomic shuffles involved, however, are different resulting in size difference of the unit cells. These differences might originate from changes in electronic structure. These are sensitive to atomic location of the third element. The site occupancy is determined recently by the ALCHEMI technique(22,46). How these results affect $M s$ temperature and R-phase transformation should still be clarified.

Alloying Ti-Ni with $\mathrm{X}=\mathrm{Cu}, \mathrm{Pd}, \mathrm{Pt}$ etc. changes the structure of the martensite into the orthorhombic $\mathrm{B} 19$ structure. In the case of $\mathrm{Cu}$ additions above $10 \%$ the lattice parameters do not vary and are close to those of binary $\mathrm{Ti}-\mathrm{Ni}$, except that $\beta=90^{\circ}$. For Ti-Ni-10Cu the lattice parameters were: $a=0.2881, b=0.4279$ and $c=0.4515 \mathrm{~nm}$. The R-phase can appear in binary Ti-Ni and some Ti-Ni-X alloys preceding the formation of $\mathrm{B}_{19}$ or B19 martensite. It is a rhombohedral distortion of the B2 parent lattice along the $<111>$ p direction as illustrated in fig.2.

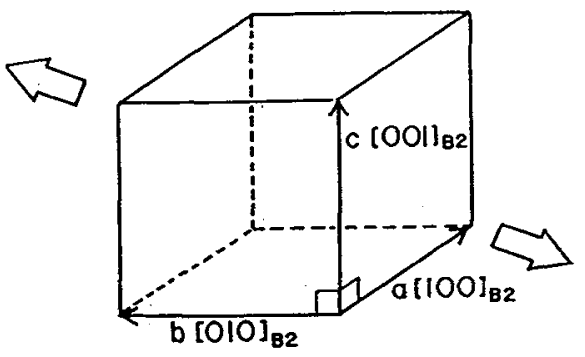

(a) $\mathrm{B2}$

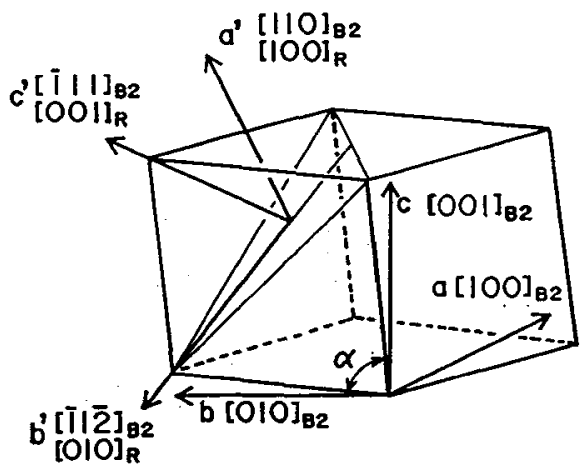

(b) R-phase

Fig. 2. Unit cell of parent B2 and R-phase. 
It can be expressed by a hexagonal unit cell with lattice parameters $a=0.738$ and $c=0.532 \mathrm{~nm}$. It belongs to the space group $\mathrm{P} 31 / \mathrm{m}$. The orientation relationship between $\mathrm{R}$-phase and parent is (111)p // (0001)h and $<211>\mathrm{p} / /<100>\mathrm{h}$. The three dimensional lattice of the R-phase has been proposed from electron diffraction patterns, accounting for the observed $\{110\}$ and $\{100\}$ B2 twins in the R-phase, with the atomic shuffles involved in the B2 $\rightarrow R$ transformation. However these shuffles do not explain fully the observed $1 / 3$ reflections $(22,43)$. Recently Fukuda et. al. showed by insitu TEM that R-phase is formed by a nucleation and growth process confirming the first order character of the transformation (40). They also showed that the $R$ phase can nucleate on a single dislocation whereas martensite can not due to the large transformation shape change compared to the strain around a single dislocation. Important to note is the temperature dependence of the lattice parameter which has a second order character. The reason for this discrepancy is not known yet. The crystal structure of the X-phase is rhombohedral within the space group R-3. The lattice parameters are $\mathbf{a}=0.6704 \mathrm{~nm}$ and $\alpha=113.85$. The orientation relationship between $X$-phase and parent (B2) is $(100)_{\mathrm{X}} / /(142)_{\mathrm{P}}$ and $[001]_{X} / /[012]_{\mathrm{P}}(23,41)$. The habit plane of the precipitate is $\{111\} \mathrm{B}_{2} \cdot\left((001)_{\mathrm{X}}\right.$ in hexagonal indices). The strain fields produced by the coherent $\mathrm{X}$-phase are important in producing the allround shape memory effect (15).

\subsection{Martensitic transformations.}

Martensite is formed from the parent phase in such a way that their interface becomes an undistorted plane (habit plane) in order to minimize the strain energy. In order to form such a martensite variant (habit-plane variant) it is necessary to introduce a lattice invariant shear like twins, stacking faults or dislocations. In shape memory alloys the lattice invariant shear is generally twinning, which is reversible. The crystallography of the martensitic transformation is well understood by the phenomenological crystallographic theories $(3,29,30)$. Recently Otsuka re-examined the crystallography of thermoelastic martenstic transformations taking the theory of deformation twinning, developed by Bilby and Crocker as a basis when considering the invariant shear (17).

The transformation modes can be described by the following five twinning elements: $K_{1}$ (invariant shear plane), $\mathrm{K}_{2}$ (another undistorted plane), $\eta_{1}$ (direction of shear), $\eta_{2}$ (intersection of $K_{2}$ and the plane of shear which is the plane normal to $K_{1}$ containing $\eta_{1}$ ) and the twinning shear S. When the parent lattice is distorted by the shearing process three different shearing modes can occur: Type I, Type II and compound twinning. These are illustrated in Table 1.

Table 1. Twinning of Ti-Ni martensite (42)

\begin{tabular}{|c|c|c|c|c|c|c|c|}
\hline I winning mode & $K_{1}$ & $\ddot{\eta}_{1}$ & $K_{2}$ & $\eta_{2}$ & $s$ & Sol.* & Ref. \\
\hline$\{\overline{1} \overline{1} 1\}$ & $\left(\begin{array}{lll}\overline{1} & \overline{1} & 1\end{array}\right)$ & {$\left[\begin{array}{lll}0.54043 & 0.45957 & 1\end{array}\right]$} & $\left(\begin{array}{llll}0.24695 & 0.50611 & 1\end{array}\right)$ & {$\left[\begin{array}{lll}2 & 1 & 1\end{array}\right]$} & 0.30961 & yes & (10) \\
\hline Type I & $\left(\begin{array}{lll}\overline{1} & 1 & 1\end{array}\right)$ & {$\left[\begin{array}{lll}0.54043 & \overline{0.45957} & 1\end{array}\right]$} & $(0.24695 \overline{0.5 \overline{0611}} 1)$ & {$\left[\begin{array}{lll}\overline{2} & 1 & 1\end{array}\right]$} & 0.30961 & yes & (10) \\
\hline$\{111\}$ & $\left(\begin{array}{lll}1 & 1 & 1\end{array}\right)$ & {$\left[\begin{array}{lll}1.51172 & 0.51172 & 1\end{array}\right]$} & $\left.\begin{array}{llll}0.66875 & 0.33750 & 1\end{array}\right)$ & {$\left[\begin{array}{lll}2 & 1 & 1\end{array}\right]$} & 0.14222 & no & (13) \\
\hline Type 1 & $\left(\begin{array}{lll}1 & \overline{1} & 1\end{array}\right)$ & {$\left[\begin{array}{lll}\overline{1.51172} & \overline{0.51172} & 1\end{array}\right]$} & $(\overline{0.66875} \overline{0.33750} 1)$ & {$\left[\begin{array}{lll}2 & 1 & 1\end{array}\right]$} & 0.14222 & no & (13) \\
\hline$\{011\}$ & $\left(\begin{array}{lll}0 & 1 & 1\end{array}\right)$ & {$\left[\begin{array}{llll}1.57271 & 1 & \overline{1}\end{array}\right]$} & $(0.720531 \overline{1})$ & {$\left[\begin{array}{lll}0 & 1 & 1\end{array}\right]$} & 0.28040 & yes & (9) \\
\hline Type I & $\left(\begin{array}{lll}0 & 1 & 1\end{array}\right)$ & {$\left[\begin{array}{llll}1.5 \overline{7271} & 1 & 1\end{array}\right]$} & $\left(\begin{array}{llll}0.72053 & 1 & 1\end{array}\right)$ & {$\left[\begin{array}{lll}0 & 1 & 1\end{array}\right]$} & 0.28040 & yes & (9) \\
\hline$\langle 011\rangle$ & $(0.72053 \quad 1 \quad \overline{1})$ & {$\left[\begin{array}{lll}0 & 1 & 1\end{array}\right]$} & $\left(\begin{array}{lll}0 & 1 & 1\end{array}\right)$ & {$\left[\begin{array}{llll}1.57271 & 1 & 1\end{array}\right]$} & 0.28040 & yes & (10) \\
\hline Type LI & $(0.72053 \quad 11)$ & {$\left[\begin{array}{lll}0 & 1 & 1\end{array}\right]$} & $\left(\begin{array}{lll}0 & 1 & 1\end{array}\right)$ & {$\left[\begin{array}{lll}1.57271 & 1 & 1\end{array}\right]$} & 0.28040 & yes & (10) \\
\hline \multirow[t]{2}{*}{ Compound } & $\left(\begin{array}{lll}0 & 0 & 1\end{array}\right)$ & {$\left[\begin{array}{lll}1 & 0 & 0\end{array}\right]$} & $\left(\begin{array}{lll}1 & 0 & 0\end{array}\right)$ & {$\left[\begin{array}{lll}0 & 0 & 1\end{array}\right]$} & 0.23848 & no & $(10)$ \\
\hline & $\left(\begin{array}{lll}1 & 0 & 0\end{array}\right)$ & {$\left[\begin{array}{lll}0 & 0 & 1\end{array}\right]$} & $\left(\begin{array}{lll}0 & 0 & 1\end{array}\right)$ & {$\left[\begin{array}{lll}1 & 0 & 0\end{array}\right]$} & 0.23848 & no & present \\
\hline
\end{tabular}

* Existence of a solution for the phenomenological crystallographic theory. 
The habit plane is formed to make the energy of the interface between parent and martensite phase nearly zero. Since the martensite transformation is accompanied by a large shear strain, martensite variants form a self-accomodating group in order to minimize the macroscopic shape change. The formation of these self-accomodating morphologies in Ti-Ni were not well understood. It is only recently that from single crystal work the self-accomodating morphologies associated with the R-phase as well as the martensite are fully analyzed. The R-phase variants form a cross-marked self-accomodating morphology consisting of four variants. The twinning planes were established as $\{110\}$ and $\{100\}$ which combine variants with twinning relationship. The resulting shape strain was nearly zero $(6,8,40,43)$. See Figure 3 .

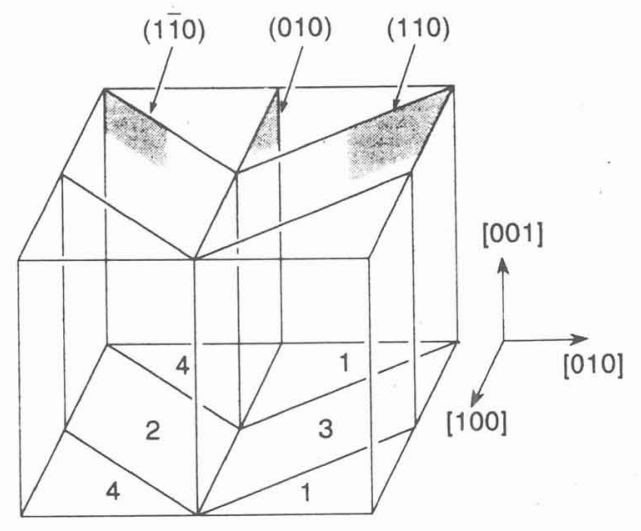

Figure 3. Self-accomodation in R-phase. 1, 2, 3, 4. R-phase variants (40).

For the B19' martensite 12 correspondences exist with the parent B2-phase. A martensite variant is formed by combining two of the 12 lattice correspondences resulting in 24 martensite variants. The observations show that 3 or 4 martensite variants, forming a self-accomodating group, cluster around one of the three $\{001\}$ B2 poles. The other available possibilities, either $\{011\}$ or $\{111\}$, have not been observed. The observed twinning modes in these groups are $<011\rangle_{M}$ Type II and $\{001\}_{M}$ Type I compound twin. The calculated shape strains are very small although non-zero. There are thus 48 possible combinations in all to form such a triangular morphology.

Otsuka showed that <011> Type II twinning is the lattice invariant shear by which excellent agreement is found between experiment and theory. In Ti-Ni alloys (11-1) $)_{M}$ Type I twinning was found generally but after carefull analysis of electron diffraction patterns Knowles and Smith (44) proved that Type II twinning is also one of the lattice invariant shears. However recent TEM and HREM work of Onda et al. (42) showed that in polycrystalline material the $\{11-1\}$ Type I twinning is also a lattice invariant shear (47). Additionally they found a new type if twinning: a (100) Type I or compound twin. The phenomenological theory does not show any solution for (100) compound twin which is a conjugate to the (001) compound twin. They therefore interpreted it as a deformation twin introduced as a result of elastic interactions during the martensitic transformation.

In Ni-Ti-Zr alloys B19' martensite is formed. The monoclinic angle $\boldsymbol{B}$ is increasing with increasing $\mathrm{Zr}$ content up to $B=104^{\circ}$ at 20 at\% $\mathrm{Zr}$. The twinning elements found in these alloys were (011) $)_{M}$ Type I twinning and (001) $)_{M}$ compound twinning. No (11-1) $)_{M}$ Type I and [011] Type II twinning were found (48). 
Other martensite structures have been found recently in TEM with different orthorhombic lattices which might be a thin foil effect $(45,46)$.

Recently Saburi (11) reported the self-accomodating morphology in the Ti-Ni-Cu alloy, the lattice correspondence being $[001] \mathrm{p} \rightarrow[100]_{\mathrm{M}},[1,-1,0] \mathrm{p} \rightarrow[010]_{\mathrm{M}},[110] \mathrm{p} \rightarrow[001]_{\mathrm{M}}$. In this case there are six equivalent lattice correspondences between the orthorhombic B19 martensite and the B2 parent phase. The six variants of the B19 are twin-related to each other with either of the two types of twinning modes: (111) [211] Type I and (011) [011] compound twin. The selfaccomodating morphology is shown in Figure 4 where variants $2-4$ have a twin relation (111) $[211]_{M}$ and variants $3-4$ twin relation $(011)_{M}[011]_{M}$. No $(010)$ twin plane did exist for the orthorhombic lattice. One of the principal lattice distortions is unity and therefore satisfies the condition for an undistorted plane to exist in the transformation, so no additional lattice invariant shear is required. This explains why no internal defects have been observed in the martensite plates in early stages of the transformation.

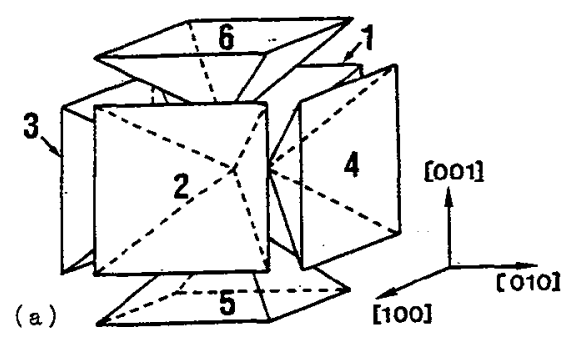

(b)

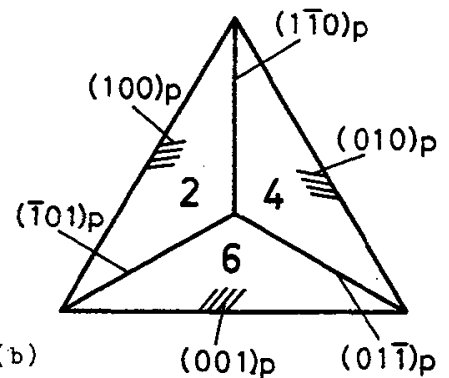

Figure 4. a) Self-accomodation in the B19-martensite. b) View from [111]p orientation (11).

\subsection{Shape memory mechanism.}

Each martensite variant forming a habit plane generally consists of two correspondence variants having a twinning relationship with each other. The correspondence variant of the $R$-phase however forms one habit plane variant in Ti-Ni. Each habit plane variant is connected to an other variant by a twinning plane. On loading, these twin planes will move easily at a relatively low stress resulting in the most favourable martensite or R-phase variant. The movement of the twin planes within the variant results in the most favourable correspondence variant. In this way the maximum recoverable strain is attained. The maximum recoverable strain is calculated with the help of the lattice distortion and the shear component parallel to the basal plane of the martensite. The representation of these calculations are given in Figure 5.

The calculated values in Figure 5 for the recoverable strain are predictions for a single crystal. 

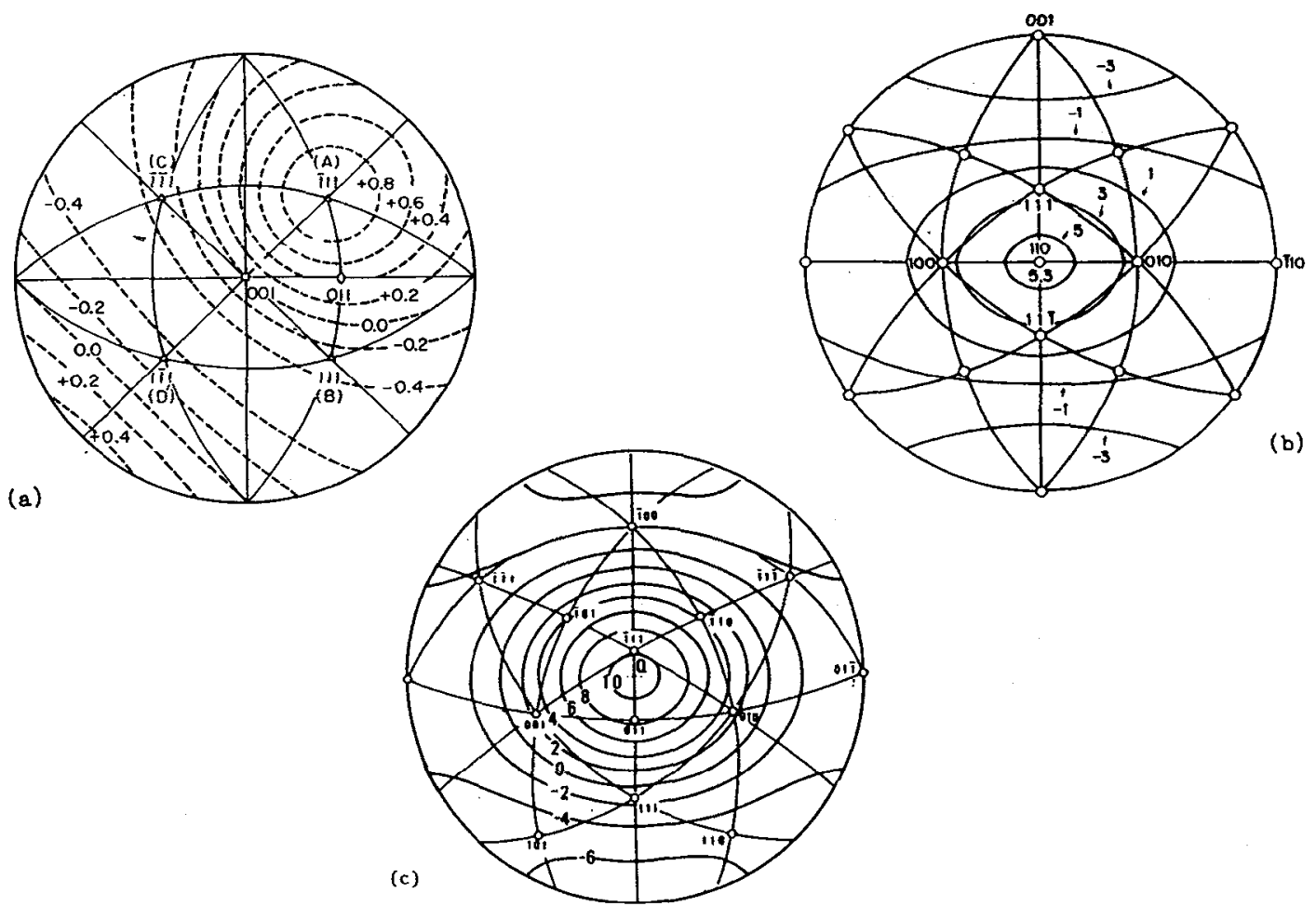

Figure 5. Calculated maximum recoverable strain for (a) R-phase (Ti-Ni), (b) B19 (Ti-40Ni$10 \mathrm{Cu}$ ) and (c) B19' (Ti-Ni) martensite formation

\subsection{Grainsize and texture effects.}

Saburi et al [50] have shown by tensile testing that single crystals of Ti $50.5 \mathrm{Ni}$ do not show pseudoelasticity at any temperature whereas polycrystalline specimens show complete pseudoelasticity above Af. Reduction of grainsize seems to be very effective in technological materials to improve pseudoelastic and other mechanical properties of SMA's. Grainrefining by RS- or PMtechnologies is chalenging.

Most of the shape memory materials for technical use are in polycrystalline state. Most production techniques produce a preferred orientation in the fine grained material. The predicted maximum recoverable strains for different martensite single crystals are shown in fig.5. The recoverable contractions for monoclinic martensite in binary $\mathrm{Ti}-\mathrm{Ni}$ are: $4.2 \%$ along [001], 5.2\% along [011] and 3.6\% along [111] (9).

This knowledge can help in explaining the effect of texture on the memory capacity of polycrystalline materials. The textures found in hot rolled and recrystallized material produced by casting or rapid solidification were described as $\{112\}<110>\mathrm{p}$ or $\{110\}<1-10>\mathrm{p}(51,52)$. Recently Mulder et al determined the texture of cold rolled 50.8Ti-Ni alloy as $\{110\}<1-10>p$ by X-ray diffraction (36) as well as the influence of thermal fatigue on texture (24). Generally more than one texture will be observed depending on the amount of deformation which effect the final recoverable strains. This is illustrated in fig.6 where the anistropy of the Schmid factor is calculated using [011] type II twinning. 

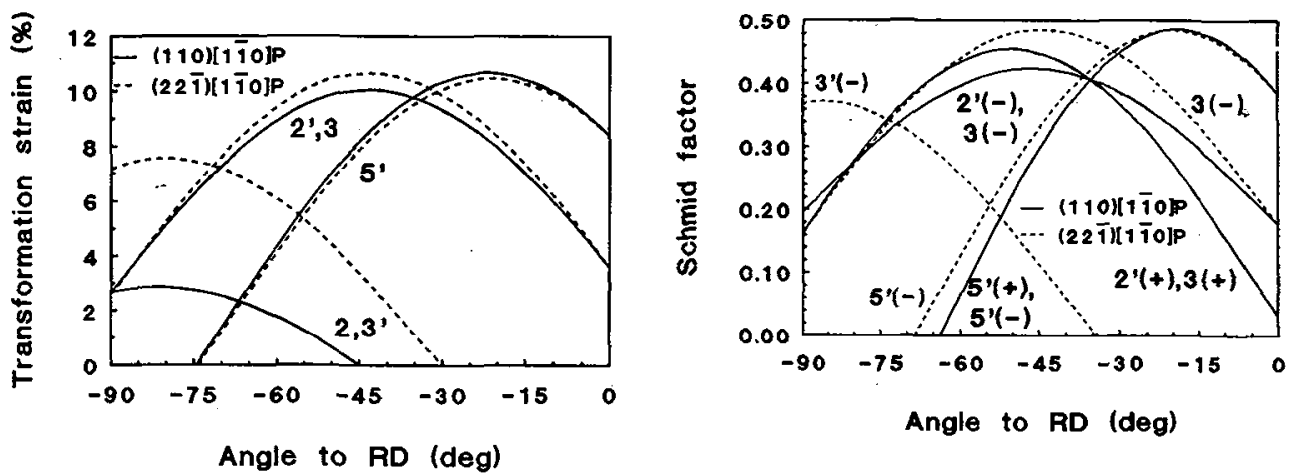

Fig.6 a) Theoretical anisotropy of maximum transformation strain for (110)[1-10]p and (22-1) [1-1 0$] p$ texture.

b) Anisotropy of the Schmid factor for induction of the most favourable habit plane variants.

The results showed that directions near the transverse direction of a rolled sheet are most favourable for thermal fatigue behaviour with low creep rate and small memory loss. The development of "two-way" memory is slow in this direction. More precise measurements of the texture evolution in various processing techniques in order to predict the memory characteristics of the produced material by modelling are needed.

\subsection{Ternary Ti-Ni-X alloys.}

Recently within this group of materials those suitable for high temperature applications have received increasing attention. Particularly the Ti-Ni-(Zr, Hf) $(25,48)$ and the Ti-Ni-(Pd, Pt, Au) $(26,27,28)$ were investigated. For the $(\mathrm{Zr}$, Hf) alloys monoclinic martensites have been observed with an increasing monoclinic angle as shown together with the $\mathrm{M}_{\mathrm{s}}$ variation with $\mathrm{Z}_{\mathrm{r} \text {-content in }}$ fig.7.
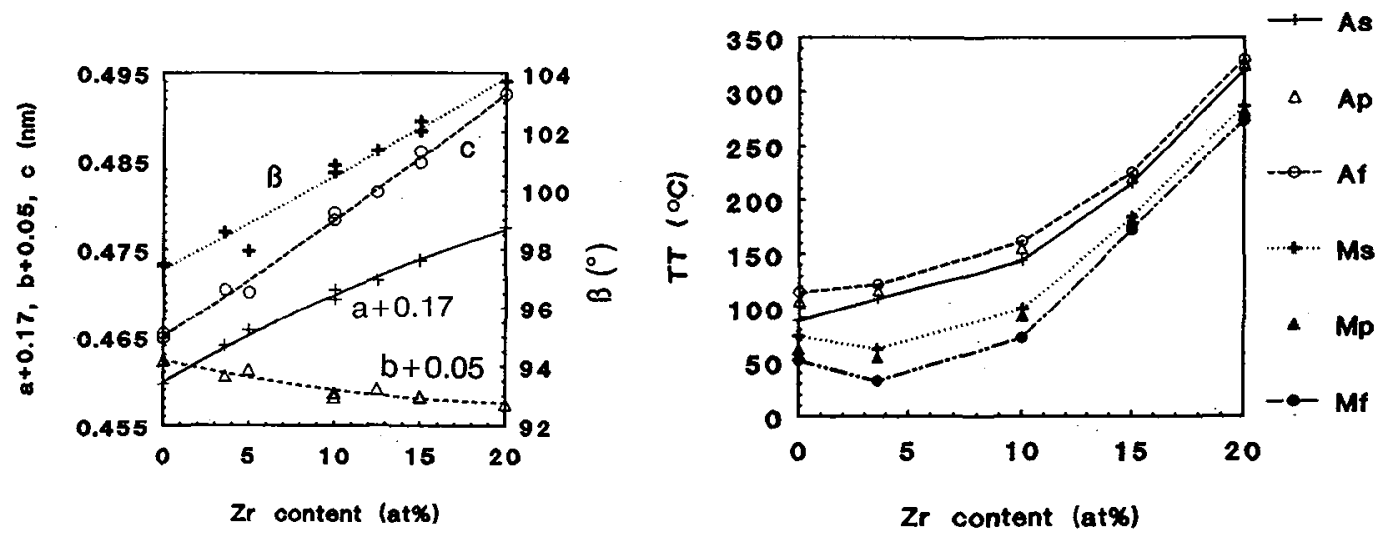

Fig 7. Ti-Ni-Zr. Lattice parameter and transformation temperatures as a function of $\mathrm{Zr}$ content. 
In a Ni47Ti33Hf20 alloy with $\mathrm{As}=208^{\circ} \mathrm{C}$, Wu showed a recovery rate up to $2.5 \%$ induced strain. Although $\mathrm{Zr}$ and $\mathrm{Hf}$ have similar behaviour, they reported the martensite structure as orthorhombic B19 in contrast to the monoclinic B19' in Ti-Ni-Zr alloys.

The twinning elements (011)M type I and (001)M compound twins have been identified in TEM suggesting that (001)M is the lattice invariant shear.

In the case of $\mathrm{X}=\mathrm{Pd}, \mathrm{Pt}$ or $\mathrm{Au}$, Lindquist $(26,27)$ showed for $\mathrm{Pd}$ and $\mathrm{Pt}$ contents above 20 at\% the presence of orthorhombic B19 martensite with internal (-111)M twins. $\mathbf{M}_{s}$ temperatures varied from $\mathrm{RT}$ to $560^{\circ} \mathrm{C}$ (for $\mathrm{Pd}$ ) and $1040^{\circ} \mathrm{C}$ (for $\mathrm{Pt}$ ). A negative volume change of $0-0.7 \%$ was determined. In a Ti50Ni40Au10 alloy Wu et al (53) reported monoclinic martensite with (-111)M internal twins. The presence of other twinning systems was not confirmed. Recently Goldberg (28) characterized the SME capabilities of Ti50Ni20Pd30 alloy with $\mathrm{Ms}=245^{\circ} \mathrm{C}$. They observed a shape memory strain up to $4 \%$ obtained after $7 \%$ deformation at $170^{\circ} \mathrm{C}$.

More precise measurements of the crystallography of the martensites in these alloys and extensive characterization is needed before the applicability of these promising alloy systems can be confirmed.

\section{References.}

[1]. W.J. Bueler, J.V. Gilfrich and K.C. Weiley, J. Appl. Phys., 34 (1963) pp. 1467-1474.

[2]. T.W. Duerig, K.N. Melton, D. Stockel and C.M. Wayman, Engineering aspects of Shape Memory Alloys, (Butterworth- Heinemann, 1990).

[3]. H. Funakubo, Shape memory alloys, (Gordon and Breach Science Publishers, 1984)

[4]. M. Nishida, C.M. Wayman and T. Honma, Metallography, 19 (1986) pp. 99-113.

[5]. S. Miyazaki, S. Kimura and K. Otsuka, Phil. Mag.A. 57, (1988) pp. 467-478.

[6]. S. Miyazaki and C.M. Wayman, Proc. ICOMAT '86, pp. 665-670.

[7]. C.M. Wayman, ibid, pp. 645-652.

[8]. S. Miyazaki, K. Otsuka and C.M. Wayman, ISIJ. International, 29 (1989) pp. 423-429.

[9]. T. Saburi, MRS Int'l Mtg.on Adv. Mats. 9, (1989) pp. 77-92.

[10]. W. Moberly and K. Melton, Engineering aspects of Shape Memory Alloys, (ButterworthHeinemann, 1990) pp. 46-57.

[11]. T. Saburi, Proc. ICOMAT 92, (1993) pp. 857-869.

[12]. T.H. Nam, T. Saburi, Y.Nakata and K. Shimizu, Mat. Trans. JIM. 31, (1990) pp. 10501056.

[13]. V.N. Khachin Revue Phys. Appl. 24, (1989) pp. 773-739

[14]. M. Nishida, C.M. Wayman and T. Honma 91, Met. Trans. 17A (1986) pp. 1505-1513.

[15]. T. Honma, Proc. ICOMAT 86, (1987) pp. 709-716.

[16]. N. Wade, Y. Adachi and Y. Hosoi, Scripta Met et. Mater. 24 (1990) pp. 1051-1055.

[17]. K. Otsuka, Mat. Sci. Forum, 56-58 (1990) pp. 393-404.

[18]. Y. Kudoh, M. Tokonami, S. Miyazaki and K. Otsuka, Acta Metall. 33 (1985) pp. 20492056

[19]. S. Miyazaki and K. Otsuka, ISIJ. International 29 (1989) 353-377.

[20]. S. Miyazaki and K. Otsuka, Acta Metall. 37 (1989) pp. 1873-1884 and pp. 1885-1890.

[21]. T. Saburi and S. Nenno, Solid-solid phase transformations, (Soc. AIME, 1982) pp. 14551479.

[22]. K. Shimizu and T. Tadaki, Materials Transactions JIM. 23 (1992) pp. 165-177.

[23]. T. Saburi, MRS Int'l Mtg. on Adv. Mats. 9 (1989) pp. 77-91.

[24]. J.H. Mulder, P.E. Thoma and J. Beyer, Mater. Char. 32 (1994) pp. 161-168.

[25]. J.H. Mulder, J.H. Maas and J. Beyer, Proc. ICOMAT 92 (1993) pp. 869-874.

[26]. P.G. Lindquist and C.M. Wayman, MRS Int'l Mtg. on Adv. Mats, 9 (1989) pp. 123-128. 
[27]. P.G. Lindquist and C.M. Wayman, ibid, pp. 129-134.

[28]. D. Golberg, Y. Yu, Y. Murakami, S. Morito and K. Otsuka, Scripta Met. et. Mater. 30 (1994) pp. 1349-1354.

[29]. Z. Nishiyama, Martensitic transformations, (Academic Press, 1978)

[30]. C.M. Wayman, Introduction to the crystallography of Martensitic Transformations, (Mac Millian, 1964).

[31]. E. Goo and R. Sinclair, Acta Metall. 33 (1985) p. 171.

[32]. S. Myazaki and K. Otsuka, Proc. 1st Japan intern. SAMPE Symposium (1989) pp. 211218.

[33]. S. Myazaki, Y. Jgo and K. Otsuka, Acta metall. 34 (1986) pp. 2045-2051.

[34]. P.E. Thoma, M. Kao, S. Fariabi and D.N. Abyudom, Proc. ICOMAT '92 (1993) pp. 917922.

[35]. M. Nishida and T. Honma, Scripta Met. 18 (1984) pp. 1293-1298.

[36]. J.H. Mulder, P.E. Thoma and J. Beyer, Z. Metalkunde 84 (1993) pp. 501-508.

[37]. M. Nishida and C.M. Wayman, Proc. ICOMAT '86, (Japan Inst. of Metals, 1987) pp. 653658.

[38]. K.Otsuka, T. Sawamira and K. Shimizu, Phys. Stat. Sol.(a) 5 (1971) pp. 457-464.

[39]. K. Otsuka and T. Ohba, Proc. ICOMAT '92 (Inst. for Advanced Studies, 1993) pp. 221232.

[40]. T. Fukuta, T. Saburi, K. Doi and S.Nemmo, Mater. Trans. JIM. 33 (1992) pp. 271-277.

[41]. M. Nishida, C.M. Wayman, R. Kaimma and T. Homma, Scripta Met. 20 (1986) pp. 899904.

[42]. T. Onda, Y. Bando, T. Dhba and K. Otsuka, Mater. Trans. JM 33 (1992) pp. 354-359.

[43]. S. Miyazaki and C.M. Wayman, Acta Metall 36 (1988) pp. 181-192.

[44]. K.M. Knowles and D.A. Smith, Acta Metall (1981) pp. 101-110.

[45]. T. Tadaki, S. Yamanoto and K. Shimizu, MRS Symp. Proc. 246 (1992) pp. 219-224.

[46]. L. Toth and J. Beyer, Scripta Met. et Mater. 25 (1991) pp. 425-430.

[47]. M. Nishida, K. Yamanoto, A. Chiba and Y. Higashi, Proc. ICOMAT'92 (Inst. for Advanced Studies, 1993) pp. 881-886.

[48]. J.H. Mulder - Investigation on high temperature shape memory alloys using Ni-Ti-Zr and Ni-Ti-Hf system, Ph.D. Thesis, Universiteit Twente, Netherlands, 1994.

[49]. Y. Nakata, T. Tadaki and K. Shimizu, Mat. Trans. JIM 32 (1991) pp. 580-586.

[50]. T. Saburi, M. Yoshida and S. Nenno, Scripta Met. 18 (1984) pp. 363-368.

[51]. L.A. Monasevich, Yu.N. Paskal, V.E. Prib, G.D. Timonim and D.B. Chernov, Metalloved. i. Termicheskaya, Obrabolka Metallov. 9 (1979) pp. 62-69.

[52]. S. Eucken and J. Hirsch, Materials Science Forum 56-58 (1990) pp. 427-492.

[53]. K.H. Wu, Z. Pu, H.K. Tseng and F.S. Biancannello, SMST conf, March 6-10, Monlerey, USA, (1994), to be published. 